\title{
Awareness on HIV Among Undergraduates: A Questionnaire Based Study
}

\section{Roopam Saini ${ }^{1 *}$, Upasana Sethi Ahuja ${ }^{2}$, Nidhi Puri Narang ${ }^{3}$, Smiti Rekha Das ${ }^{1}$, Dipshikha Das ${ }^{4}$ and Akansha Budakoti ${ }^{5}$}

${ }^{1}$ PG Student, Department of Oral Medicine and Radiology, I.T.S Dental College, Muradnagar, Ghaziabad, India

${ }^{2}$ Professor and Head, Department of Oral Medicine and Radiology, I.T.S Dental

College, Muradnagar, Ghaziabad, India

${ }^{3}$ Professor, I.T.S Dental College, Muradnagar, Ghaziabad, India

${ }^{4}$ PG Student, Department of Public Health Dentistry, I.T.S Dental College,

Muradnagar, Ghaziabad, India

${ }^{5}$ Senior Lecturer, Department of Oral Medicine and Radiology, K M Shah Dental

College, Piparia, Vadodara, Gujarat, India

*Corresponding Author: Roopam Saini, PG Student, Department of Oral Medicine and Radiology, I.T.S Dental College, Muradnagar, Ghaziabad, India.
Received: September 24, 2021

Published: October 20, 2021

(C) All rights are reserved by Roopam Saini., et al.

\section{Abstract}

Aim and Objectives: To investigate knowledge, attitude and behaviour regarding HIV among undergraduate students.

Materials and Methods: A descriptive questionnaire based study was conducted in the I.T.S Dental College among Physiotherapy and Dental undergraduate students. The students were divided into 5 groups i.e. BPT $1^{\text {st }}, 2^{\text {nd }}, 3^{\text {rd }}$ years, Interns and BDS Interns. 20 close ended multiple choice questions evaluating the spread, source, social awareness and investigation of HIV were distributed among the participants. ANOVA test was used for the comparison of the mean values among all the groups. Level of statistical significance was set at $\mathrm{p}$-value less than or equal to 0.05 .

Results: Significant difference in the mean was observed among all questions and mean of all total scores were compared in which BDS Interns were more aware than Physiotherapy undergraduates.

Conclusion: Despite the fact that majority of students were aware of the transmission of HIV/AIDS, this study showed that students were less likely to translate their knowledge about HIV/AIDS transmission into healthy behaviour. Health and education sectors need to be improved the way of delivering the education regarding HIV/AIDS risk awareness.

Keywords: HIV; Knowledge; Undergraduates

\section{Abbreviations}

HIV: Human Immunodeficiency Virus; AIDS: Acquired Immuno Deficiency Syndrome

\section{Introduction}

HIV is a virus that spread through certain body fluids and attacks the body's immune system, specifically the CD4 cells, often called T cells. Over time, HIV can destroy so many of these cells 
that the body can't fight off infections and disease. It targets and alters the immune system, increasing the risk and impact of other infections and diseases. This increases the risk and impact of opportunistic infections and cancers. However, a person can carry HIV without experiencing symptoms for a long time [1].

HIV is a lifelong infection. However, receiving treatment and managing the disease effectively can prevent HIV from reaching a severe level and reduce the risk of a person passing on the virus. People transmit HIV in bodily fluids, including blood, semen, vaginal secretions, anal fluids, breast milk, pregnant women to foetus and during blood transfusions [1]. Without treatment, the infection might progress to an advanced disease stage called AIDS. AIDS is the most advanced stage of HIV infection. Once HIV infection develops into AIDS, infections and cancer pose a greater risk.

Every HIV positive patient is a potential candidate for disease transmission to the attending health care professional and the risk of accidental transmission of HIV in such cases, depends on their safe practices which depends on their awareness regarding Knowledge, Attitude and Behaviour of the epidemiology of this deadly disease. The accidental transmission of HIV to health care professionals can occur during occupational exposure which is very common. Only a single awareness among health care professionals regarding HIV can prevent them and their assistants from spreading this disease [2].

HIV/AIDS can lead to a drastic changes in the oral cavity leading to oral complications like Oral Candidiasis, oral ulcers including nodular swellings [3]. As from nearly around three decades HIV/ AIDS has been shrouded in many myths and misconceptions. So, this study was conducted to assess awareness among undergraduate students in the vicinity of ITS Dental College, Muradnagar, Ghaziabad.

\section{Materials and Methods}

A survey was conducted in the vicinity of ITS Dental College, Muradnagar, Ghaziabad among 200 undergraduate students. The students were divided into 5 groups i.e. BPT $1^{\text {st }}, 2^{\text {nd }}, 3^{\text {rd }}$ years, Interns and BDS Interns.

The data collection was done by the help of questionnaire proforma. 20 close ended multiple choice questions evaluating the spread, source, social awareness and investigation of HIV were distributed among the participants.

The purpose of the study was explained to all the participants. They filled and returned it within 4 - 5 minutes. Information was collected on a pre-designed, pre-tested and self-administered questionnaire. They were informed that the whole exercise will be confidential, anonymous, voluntary and is for academic purpose. Data collected was then analysed using SPSS software.

\section{Sample size calculation}

The sample size was calculated using the $\mathrm{n}$ Master 2.0 software. The power of the study was taken to be $80 \%$ and Confidence Interval (C.I.) of $95 \%$ was taken. The sample size was estimated to be a minimum of 40 per group. The total sample size was estimated to be 200 for all the groups.

\section{Statistical analysis}

The data was entered into Microsoft Excel and analyzed using SPSS (Statistical Package for Social Sciences) version package for relevant statistical comparisons. Results presented in the form of tables and graphs.

Descriptive statistics performed by calculating mean, standard deviation, frequencies and percentages for the Continuous variables. Categorical variables summarized as frequencies and percentages.

Repeated measures ANOVA test was used for the comparison of the mean values among all the groups. Level of statistical significance was set at p-value less than or equal to 0.05 .

\section{Results}

There was a significant difference in mean of Question 1 to Question 10 score between (Table 1 and graph 1 ) BPT $1^{\text {st }}$ year, BPT $2^{\text {nd }}$ year, BPT $3^{\text {rd }}$ year, BPT Interns and BDS Interns. The mean from Question 1 to Question 10 score increased significantly from BPT $1^{\text {st }}$ year to BPT $2^{\text {nd }}$ year to BPT $3^{\text {rd }}$ year to BPT Interns to BDS Interns.

There was a significant difference in mean from Question 11 to Question 20 score between BPT $1^{\text {st }}$ year, BPT $2^{\text {nd }}$ year, BPT $3^{\text {rd }}$ year, BPT Interns and BDS Interns. The mean score increased significantly from BPT $1^{\text {st }}$ year to BPT $2^{\text {nd }}$ year to BPT $3^{\text {rd }}$ year to BPT Interns to BDS Interns. 


\begin{tabular}{|l|c|c|c|c|c|c|c|c|c|c|c|}
\hline & \multicolumn{2}{|c|}{ BPT 1 } & \multicolumn{2}{c|}{ st } & \multicolumn{2}{c|}{ BPT 2nd } & \multicolumn{2}{c|}{ year } & \multicolumn{2}{c|}{ BPT 3 } \\
& Mean & SD & Mean & SD & Mean & SD & Mean & SD & Mean & SD & p-value \\
\hline Question 1 & 1.95 & 0.36 & 2.15 & 0.40 & 2.39 & 0.46 & 2.65 & 0.56 & 2.90 & 0.70 & $0.016^{*}$ \\
\hline Question 2 & 1.98 & 0.42 & 2.18 & 0.46 & 2.42 & 0.52 & 2.68 & 0.62 & 2.98 & 0.76 & $0.024^{*}$ \\
\hline Question 3 & 1.55 & 0.00 & 1.75 & 0.04 & 1.99 & 0.10 & 2.25 & 0.20 & 2.55 & 0.34 & $0.038^{*}$ \\
\hline Question 4 & 1.78 & 0.00 & 1.98 & 0.04 & 2.22 & 0.10 & 2.48 & 0.20 & 2.78 & 0.34 & $0.010^{*}$ \\
\hline Question 5 & 1.34 & 0.00 & 1.54 & 0.04 & 1.78 & 0.10 & 2.04 & 0.20 & 2.34 & 0.34 & $0.014^{*}$ \\
\hline Question 6 & 1.00 & 0.00 & 1.20 & 0.04 & 1.44 & 0.10 & 1.70 & 0.20 & 2.12 & 0.34 & $0.022^{*}$ \\
\hline Question 7 & 2.10 & 0.30 & 2.30 & 0.34 & 2.50 & 0.40 & 2.72 & 0.50 & 2.94 & 0.64 & $0.020^{*}$ \\
\hline Question 8 & 2.00 & 0.00 & 2.20 & 0.04 & 2.44 & 0.10 & 2.70 & 0.20 & 3.00 & 0.34 & $0.024^{*}$ \\
\hline Question 9 & 1.68 & 0.00 & 1.88 & 0.04 & 2.12 & 0.10 & 2.38 & 0.20 & 2.68 & 0.34 & $0.027^{*}$ \\
\hline Question 10 & 2.00 & 0.00 & 2.20 & 0.04 & 2.44 & 0.10 & 2.70 & 0.20 & 2.95 & 0.34 & $0.030^{*}$ \\
\hline
\end{tabular}

Table 1

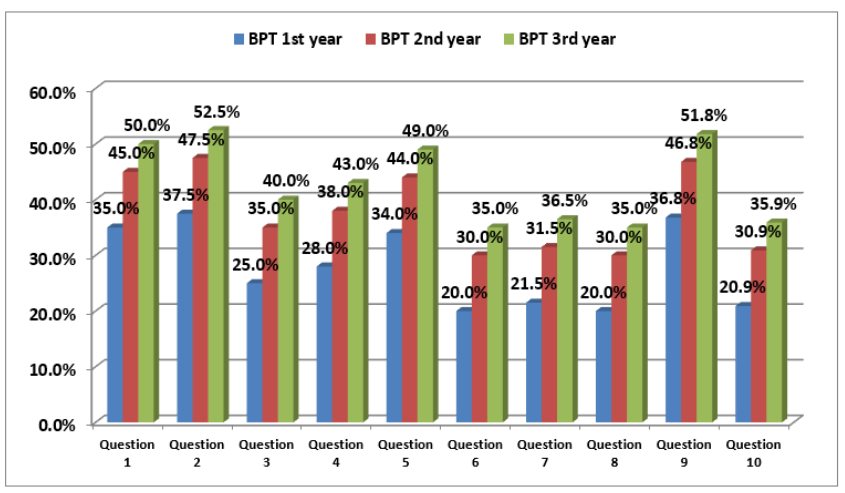

Graph 1
Table 2 and graph 2 shows the mean from Question 11 to Question 20 score increased significantly from BPT $1^{\text {st }}$ year to BPT $2^{\text {nd }}$ year to BPT $3^{\text {rd }}$ year to BPT Interns to BDS Interns.

There was a significant difference in mean questionnaire score between BPT $1^{\text {st }}$ year, BPT $2^{\text {nd }}$ year, BPT $3^{\text {rd }}$ year, BPT Interns and BDS Interns. The mean questionnaire increased significantly from BPT $1^{\text {st }}$ year to BPT $2^{\text {nd }}$ year to BPT $3^{\text {rd }}$ year to BPT Interns to BDS Interns.

Table 3 and graph 3 shows total mean score among all the five groups.

\begin{tabular}{|l|c|c|c|c|c|c|c|c|c|c|c|}
\hline & \multicolumn{2}{|c|}{ BPT 1 $^{\text {st }}$ year } & \multicolumn{2}{c|}{ BPT 2 $^{\text {nd }}$ year } & \multicolumn{2}{c|}{ BPT 3 } \\
& Mean & SD & Mean & SD & Mean & SD & Mean & SD & Mean & SD & p-value \\
\hline Question 11 & 1.79 & 0.00 & 1.99 & 0.04 & 2.23 & 0.10 & 2.49 & 0.20 & 2.79 & 0.34 & $0.015^{*}$ \\
\hline Question 12 & 2.20 & 0.41 & 2.40 & 0.45 & 2.64 & 0.51 & 2.90 & 0.61 & 3.20 & 0.75 & $0.008^{*}$ \\
\hline Question 13 & 1.88 & 0.00 & 2.08 & 0.04 & 2.32 & 0.10 & 2.58 & 0.20 & 2.80 & 0.34 & $0.029^{*}$ \\
\hline Question 14 & 2.00 & 0.00 & 2.20 & 0.04 & 2.44 & 0.10 & 2.70 & 0.20 & 3.00 & 0.34 & $0.030^{*}$ \\
\hline Question 15 & 1.55 & 0.00 & 1.75 & 0.04 & 1.99 & 0.10 & 2.25 & 0.20 & 2.55 & 0.34 & $0.028^{*}$ \\
\hline Question 16 & 2.00 & 0.00 & 2.20 & 0.04 & 2.44 & 0.10 & 2.70 & 0.20 & 2.94 & 0.34 & $0.034^{*}$ \\
\hline Question 17 & 2.02 & 0.00 & 2.22 & 0.04 & 2.46 & 0.10 & 2.72 & 0.20 & 3.00 & 0.34 & $0.040^{*}$ \\
\hline Question 18 & 1.68 & 0.00 & 1.88 & 0.04 & 2.12 & 0.10 & 2.40 & 0.20 & 2.82 & 0.34 & $0.035^{*}$ \\
\hline Question 19 & 1.80 & 0.00 & 2.00 & 0.04 & 2.24 & 0.10 & 2.50 & 0.20 & 2.80 & 0.34 & $0.022^{*}$ \\
\hline Question 20 & 1.77 & 0.00 & 1.97 & 0.04 & 2.21 & 0.10 & 2.52 & 0.20 & 2.82 & 0.34 & $0.019^{*}$ \\
\hline
\end{tabular}

Table 2 


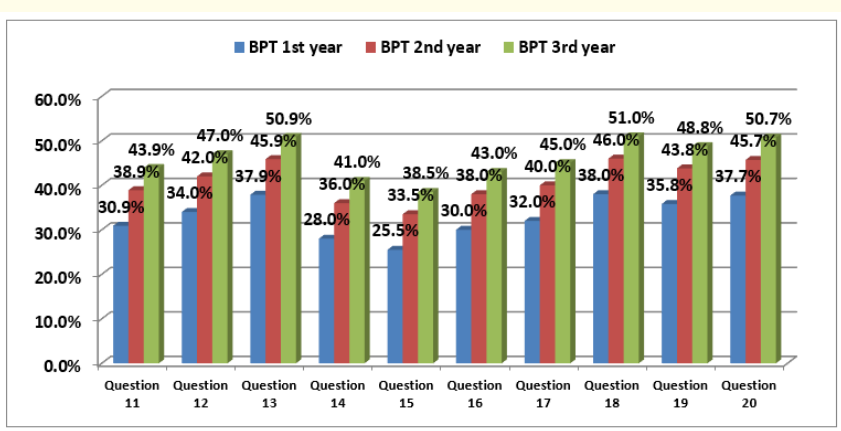

Graph 2

\section{Discussion}

According to world health organization, it is estimated globally that 37.9 million people live with HIV, 1.8 million are newly infected and 32 million HIV related deaths had occur till 2018. In India, HIV prevalence of $0.26 \%$ in the adult population, an estimation of 2.1million people living with HIV in 2018 has been estimated [4].

A study was conducted by Ammar N., et al. in 2015 to assess awareness in Iraqi medical and Dental students and the study concluded that more emphasis should be placed on educating dental and medical students about HIV and other blood-borne infections [5].

\begin{tabular}{|c|c|c|c|c|c|c|c|c|c|c|c|}
\hline & \multicolumn{2}{|c|}{ BPT $1^{\text {st }}$ year } & \multicolumn{2}{|c|}{ BPT $2^{\text {nd }}$ year } & \multicolumn{2}{|c|}{ BPT $3^{\text {rd }}$ year } & \multicolumn{2}{|c|}{ BPT Intern } & \multicolumn{2}{|c|}{ BDS Intern } & \multirow{2}{*}{ p-value } \\
\hline & Mean & SD & Mean & SD & Mean & SD & Mean & SD & Mean & SD & \\
\hline $\begin{array}{l}\text { Total } \\
\text { score }\end{array}$ & 36.07 & 5.70 & 40.07 & 5.74 & 44.83 & 5.80 & 50.06 & 5.90 & 55.96 & 6.04 & $0.002^{*}$ \\
\hline
\end{tabular}

Table 3

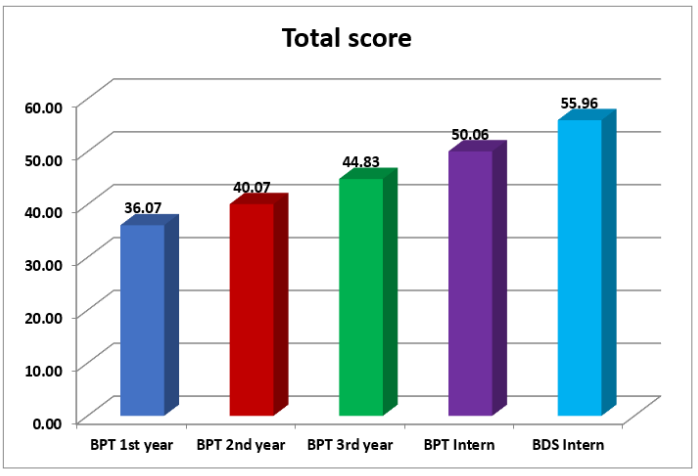

Graph 3
Hasham Akram., et al. in 2015 conducted a study and concluded that undergraduate students were less likely to translate their knowledge about transmission of HIV/AIDS into healthy behaviour, therefore health and education sectors need to be improved [1].
Santosh Kumar., et al. in 2016 conducted a study on awareness of HIV among undergraduates and concluded that HIV/AIDS related knowledge and attitudes among dental students are comparable to other studies from Saudi but are poor when compared to other countries [6]. In our study, the basic information about the disease like causative agent, modes of transmission etc. were known to most of the participants, deficiencies in their knowledge and awareness in many critical areas of the disease were noticed. When all the 5 five groups were compared the mean significant difference was observed among all the groups. With regard to first 10 questions there was a significant difference in mean score increased significantly from BPT $1^{\text {st }}$ year to BPT $2^{\text {nd }}$ year to BPT $3^{\text {rd }}$ year to BPT Interns to BDS Interns (Graph and table 1). Similarly, for the questions from 11 to 20 there was a significant difference in mean score increased significantly from BPT $1^{\text {st }}$ year to BPT $2^{\text {nd }}$ year to BPT $3^{\text {rd }}$ year to BPT Interns to BDS Interns (Graph and table 2). And also on comparing the mean total score among all the 5 groups, there was a significant difference in mean questionnaire score between BPT $1^{\text {st }}$ year, BPT $2^{\text {nd }}$ year, BPT $3^{\text {rd }}$ year, BPT Interns and BDS Interns. The mean questionnaire increased significantly 
from BPT $1^{\text {st }}$ year to BPT $2^{\text {nd }}$ year to BPT $3^{\text {rd }}$ year to BPT Interns to BDS Interns (Graph and table 3).

And also on comparing total mean score of all the groups BDS Interns showed more awareness as compared to BPT students and a reason for it may be the lack of enough education and knowledge.

These deficiencies in their knowledge may influence their behaviour and make them expose to risk of transmission of HIV [7]. As it is very well appreciated from this study that misconceptions regarding transmission of the disease are extremely high which can further lead to discrimination in patient's care or apprehensions and stress amongst the health care professionals while dealing with HIV positive patients.

Being in the field of medicine, there might be some kind of lack in education of HIV in their curriculum. We as a dentist should play an important role by spreading awareness of HIV by conducting school camps at secondary education level and rural camps also as low socioeconomic status people are more vulnerable to this deadly disease.

\section{Conclusion}

From outcome of this study it is clear that our efforts in spreading the knowledge about this deadly and debilitating disease have met the limited success. HIV/AIDS whose prevalence shows no signs of abating and whose potent form of prevention is only awareness as there is no specific cure for this disease till now. We recommend from our study that education about HIV should be included from the secondary education level to the curriculum to increase awareness amongst youngsters so as to prevent the risk of this deadly disease. It is utmost responsibility of we as health professionals to leave no stone unturned to aware people towards this disease while simultaneously explaining how to guard against it.

\section{Acknowledgements}

All the authors have equally contributed in collection of the sample size of the study as well as financially.

\section{Conflict of Interest}

None.
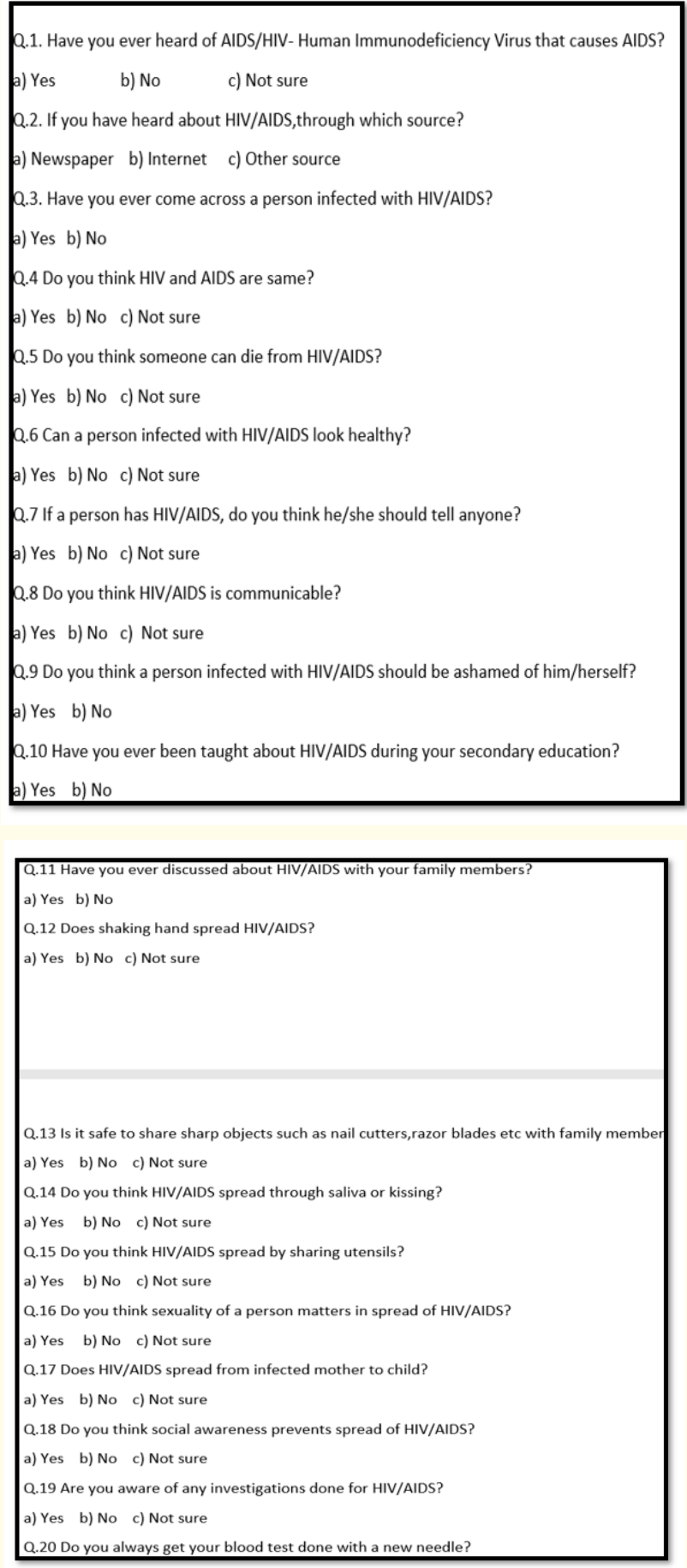

Figure

\section{Details of Questionnaire Used}




\section{Bibliography}

1. Choudhary HA., et al. "Knowledge, behaviour and attitudes regarding HIV/aids among undergraduate students in an Irish university". International Journal of Surgery and Medicine 1.2 (2015): 58-66.

2. Rosiek A., et al. "Occupational HIV risk for health care workers: risk factor and the risk of infection in the course of professional activities". Therapeutics and Clinical Risk Management 12 (2016): 989-994.

3. Leao JC., et al. "Oral complications of HIV disease”. CLINICS 64.5 (2009): 459-470.

4. Singh VP., et al. "Knowledge and Attitude of Dental Students towards HIV/AIDS Patients in Melaka, Malaysia". Malaysian Journal of Medical Sciences 24.3 (2017): 73-82.

5. Albujeer A N., et al. "HIV/AIDS awareness among Iraqi medical and dental students". Journal of International Society of Preventive and Community 5.5 (2015): 372-376.

6. Kumar S., et al. "Knowledge and attitudes towards HIV/AIDS among dental students of Jazan University, Kingdom Saudi Arabia”. The Saudi Dental Journal 30.1 (2018): 47-52.

7. Ozge T., et al. "Knowledge, attitudes and behaviour of students from a medicine faculty, dentistry faculty, and medical technology vocational training school toward HIV/AIDS". International Journal of Occupational and Environmental Health 23.2 (2010): $153-160$.

Volume 5 Issue 11 November 2021

(C) All rights are reserved by Roopam Saini., et al. 